\title{
Sandra Campagna, Giuliana Garzone, Cornelia Ilie and Elizabeth Rowley-Jolivet (eds.), Evolving Genres in Web-mediated Communication
}

Bern, Berlin, Brussels, Frankfurt am Main, New York, Oxford, Vienna: Peter Lang, Linguistic Insights 140, 2012

John Humbley

\section{OpenEdition \\ Journals}

Electronic version

URL: http://journals.openedition.org/asp/3792

DOI: $10.4000 /$ asp.3792

ISSN: 2108-6354

Publisher

Groupe d'étude et de recherche en anglais de spécialité

Printed version

Date of publication: 1 November 2013

Number of pages: 185-191

ISSN: 1246-8185

Electronic reference

John Humbley, « Sandra Campagna, Giuliana Garzone, Cornelia Ilie and Elizabeth Rowley-Jolivet

(eds.), Evolving Genres in Web-mediated Communication », ASp [Online], 64 | 2013, Online since 01

November 2013, connection on 02 November 2020. URL : http://journals.openedition.org/asp/3792 ; DOI : https://doi.org/10.4000/asp.3792

This text was automatically generated on 2 November 2020

Tous droits réservés 


\section{Sandra Campagna, Giuliana} Garzone, Cornelia Ilie and Elizabeth Rowley-Jolivet (eds.), Evolving Genres in Web-mediated Communication

Bern, Berlin, Brussels, Frankfurt am Main, New York, Oxford, Vienna: Peter Lang, Linguistic Insights 140, 2012

John Humbley

\section{REFERENCES}

Campagna, Sandra, Giuliana Garzone, Cornelia Ilie and Elizabeth Rowley-Jolivet (eds.). 2012. Evolving Genres in Web-mediated Communication. Bern, Berlin, Brussels, Frankfurt am Main, New York, Oxford, Vienna: Peter Lang, Linguistic Insights 140. 337 pp. ISBN 978-3-0343-1013-0. 
1 Evolving Genres in Web-mediated Communication, a volume of studies on the effects of the new media on various aspects of communication, started out as a series of papers given in two seminars of the 10th Conference of the European Society for the Study of English. It can be claimed to be a significant contribution to that branch of English for Specific Purposes focusing on genre studies, inasmuch as web-mediated communication has brought about wholesale changes to the way in which specialised knowledge is produced and exchanged, calling into question many assumptions about the nature of genre itself. The extremely useful introduction, signed by all four convenors, not only presents the thirteen chapters but also

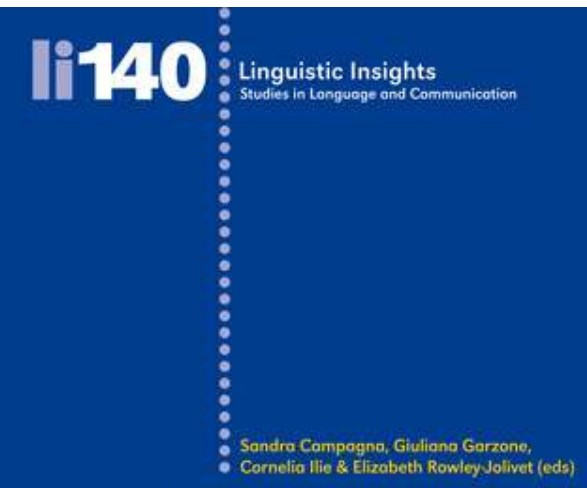

Evolving Genres

in Web-mediated

Communication

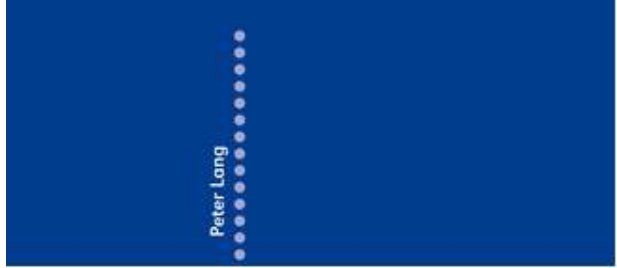
provides an overview of the development of web-based communication, the genres involved and most critically, a synopsis of some of the most significant research carried out in this new and constantly changing area, in particular in hypermedia. The work is divided up into three parts, which may be seen as partly chronological, partly thematic. The first chapters are devoted to the manifestations of genre in Web 1.0, whereas the second section is given over to the more participatory Web 2.0, with the third and final section concentrating on one particular form - which may or may not be a genre, according to the different contributors - which typifies Web 2.0, the blog and its offshoot, the microblog. It is significant that the three papers on different genres of scientific English are part of the Web 2.0 section, clearly indicating the extent of the paradigm change.

Paola Catenaccio, in "A genre-theory approach to the website: some preliminary considerations", provides a theoretical introduction to the overarching topic of webmediated communication by reviewing the considerable literature on the theory involved. It turns out that no satisfactory definition exists of what a website actually is. The author's starting point is genre theory, in particular Swales' idea of genre networks (Swales 2004: 22), and she analyses the various suggestions made to accommodate the inherently multigenre nature of the website. Her suggestion is to focus on rhetorical purpose, which lends unity to the diverse genres a website may contain, so that it can be considered a sort of rhetorical interface. The case study used to illustrate her analysis is an intriguing one: Siemens' corporate website, which opens on the Bayreuth Festival, with hyperlinks to both the operas scheduled and to more obvious sections devoted to social and financial aspects of the company's activities. All these very different sorts of genre are linked by a common rhetorical aim of projecting various aspects of one corporate image. No mention is made though of any strictly language features: if for instance the site has pages in languages other than English.

3 The point of view of the second chapter, however, is overtly multilingual. Alessandra Vicentini, in "Institutional healthcare e-brochures and multilingualism issues in the 
recent immigration era in Italy (2007-2010)", tackles both the theme of genre migration, where health information is transferred from paper to the web, and the challenges thrown down by multilingual communication brought about by the need of Italian health authorities to communicate on such matters with recent immigrants. An analysis is made of a corpus of 178 Italian health websites, interpreted in terms of move structure, purpose, contents, form and language, together with a global analysis of genre and multimodality. It turns out that the 27 languages used are almost all confined to downloadable .pdf brochures, which would be difficult to access for the non-Italian reader. The major change over the three years separating the two web corpora concerns the move of detailing content, which has been reduced and simplified, and the move of establishing contacts, which has been enhanced. The foreign language brochures are thus now seen primarily as a means for referring the immigrant to the appropriate service rather than giving any specific health care advice. Although the author refrains from making any value judgments about this evolution, it can hardly be considered to represent progress in communication.

The inclusion of a chapter on official web-based communication in China is a significant contribution to the cultural diversity of this book. Bettina Mottura provides this opening in "The Chinese government exploring genres for web-mediated communication", and shows how government websites in China are cautiously opening up to dialogue with the public, limited as it still is. To illustrate this, an account is given of three online interviews given by the Chinese Prime Minister in 2009, 2010 and 2011, answering written questions from the public. Contrary to the other papers included in this volume, the present article cannot claim to raise explicit theoretical issues and remains very largely descriptive, though usefully so, as they show how the medium influences the linguistic features observed.

5 The question of how argument is handled multimedially has been understandably little investigated compared with informative texts, making the paper by Chiara Degano, "Argumentative genres on the web: The case of two NGOs' campaigns" particularly valuable. It is especially interesting to see how multimediality and hypertextuality can be brought into the equation and the corresponding adaptation to the well-known three level model (communicative purpose, moves and rhetorical features [Swales 1990]), taking into account reading and navigation modes. It focuses on the NGOs' campaign against genetically modified food and infant formula respectively, and analyses how argument can be developed effectively in a non-linear form. Here the two examples illustrate different strategies and, which, on analysis, turn out to be very different in their effectiveness. It is found that the campaign against infant formula is held to be relatively unsuccessful, since the links provided create false expectations on the part of the reader, when for example what is presented as an argument turns out to be an expository text. The close relation between actual use of language and the various functions of the different move levels is clearly brought out with telling examples.

6 The second section moves on to Web 2.0 communication and focuses on scientific research and how it has responded to the challenge. The first chapter of this section, by Elizabeth Rowley-Jolivet, is titled "Open Science and the re-purposing of genre: an analysis of web-mediated laboratory protocols". It gives an account of the unexpected changes which occur when the lab protocol migrates to the web. As many of the chapters, this study starts off with a very useful state-of-the-art concerning current 
mutations of scientific publishing, from Open Access, where publications are freely available, to Open Science, offering a more participatory approach typical of Web 2.0. The study here, focusing on lab protocols in the field of biology, shows a remarkable mutation: from an impersonal highly-stylised genre there emerges a personalised community-oriented wiki-type communication mode in the web-based form. The analysis takes a corpus of forty online protocols from the OpenWetWare website and twenty print protocols, all from biological engineering laboratories, which are analysed from a structural and a linguistic viewpoint. It turns out that the basic structure of the lab protocol remains the backbone of the genre, but that many changes occur in both language used - which is much less regimented - and in the textual environment, embedded as it is in a wikipage, a good example of hybridization. One very satisfying feature of this chapter is the broad sweep going from the epistemology of scientific research through the evolution facilitated by web access to the actual language features, which have changed on the way.

7 It could be claimed that Wikipedia has revolutionized our use of dictionaries and encyclopaedias in a very short space of time, and that it is a matter of regret that the phenomenon has not received more scholarly interest from linguists and lexicographers in particular. It is encouraging, in this context, to see that Maristella Gatto has devoted a study to discursive features of Wikipedia. In "Centrifugal and centripetal forces in web 2.0 genres. The case of Wikipedia" the author examines the Bakhtinian concept of centrifugal and centripetal forces at work in discourse (Bakhtin 1982: 272). Centripetal forces are defined as centralising discourse, producing an "official" unitary standard language, whereas centrifugal forces decentralise and foster multiplicity in language and structural forms. The view of the way these forces play themselves out in the context of Wikipedia is analysed in conjunction with the theory of the North American New Rhetorical School, which provides a tool to analyse the dynamic natures of genres. It has been argued that web-based communication is inherently centrifugal in form, though as the case study illustrates, the same forces are at work as in the paper universe, though in a much more diverse form. Typical of Wikipedia is the blurring of distinction between producer and consumer, and the concomitant rise of the "prosumer", the consumer-provider, potentially encouraging centrifugal tendencies. To counter these, the Wikipedia has a Style Manual, Discussion pages, History of entries and other features which effectively insure a degree of structural and rhetorical cohesion and thus a form of standardisation. The case study presented here is taken from a corpus of entries on chemistry. It appears from study of the History of entries that ordinary Wikipedians play the role of enforcers of genre integrity. The article concludes on future research which could be carried out on patterns of negotiation and conflict as exemplified in particular in History of entries.

8 Enrico Grazzi in "The web as a participatory environment: social networks and 'memes' from a teacher's perspective" places his didactic proposal in a sociolinguistic framework and reflects on the intersections and interactions of the expanding circle of Englishes on the one hand and English as a Foreign Language (EFL) and English as a Lingua Franca (ELF) on the other (Kachru 1986), with respect to use made in on-line communication. The positioning of the learner within these overlapping categories is discussed in some depth, and the analysis is based on Vygotsky's sociocultural theory (Vygotsky 1962). The author is particularly careful to define to what extent users of ELF can be considered as belonging to a "community." The didactic proposal is to use Internet memes in secondary school EFL classes in order to create a "zone of proximal 
development", where the students engage in activities bringing together language awareness, media literacy and a participatory approach to crosscultural communication, thereby paving the transition from EFL to ELF. The interest of this particular contribution is not only an innovative didactic proposal, redefining the role of student and teacher (the expression facilitator is not used) but also a wide-ranging discussion of users' needs, informed through research in both didactics and sociolinguistics.

9 The pace at which the Internet changes is a real challenge for scholarly study: the objects of analysis tend to mutate or even disappear by the time the research actually gets into print. This is almost the case for Elisa Corino and Cristina Onesti's article "Agreement and disagreement in newsgroup interaction" on the use of quotations as an argumentative device in newsgroups, a web-based communication genre which may seem in 2013 to be on the way out before it could be studied adequately. As the authors point out, most of the work on this form of communication has focused on nonstandard, even sloppy language use, whereas there is much evidence shown in this study to suggest that careful strategies are indeed elaborated by the users, taking advantage of the (then) new format, an illustration of the subtheme of "affordance", which runs through this collection. The use of quotations, facilitated by the software, is analysed for strategies ranging from complete agreement to complete disagreement. Here attention is paid to the use of language markers: auxiliaries (I agree/I would agree), connectives, if-clauses, in relation to the strategy being developed. One interesting sideline of this research is the characterisation of differing strategies used by male and female users, corresponding to a great extent to popular stereotypes, and graphically illustrated by a few well chosen examples (the most extreme in Italian). This is obviously a fruitful line of research which one would like to see pursued, in spite of the difficulty in identifying the sex of the user from the screen name or other indirect clues.

The definition of what a web-based genre is and its connections to previously existing genres is a subtheme in many of the contributions to this volume, so it is appropriate that it should be the main topic of the first chapter in the section on blogs. Giuliana Garzone, in "Where do web genres come from? The case of blogs", addresses the question of the origin of genres and how their web-based representations evolve, taking the blog as a case study. The idea that some genres have been created for or indeed by the web, others adapted and others still simply transposed, is presented as oversimplistic. All genres are ultimately adaptations of previous incarnations (the ship's log...). Moreover, once a new genre becomes established it may well develop in different directions and hybridise with other forms. And this is precisely what happened with the blog. After a historical review explaining how the blog came into being, and what its defining features were initially - the blurring of the distinction between private and public spheres is particularly important in this respect - the author studies in detail two hybridised forms: the news political blog (Huffington Post) and the external corporate blog. She concludes by positing blogs as they appear now as a mega-genre, in line with Bhatia's classification (Bhatia 2005).

11 Unsurprisingly, and as it turns out felicitously, several of the topics raised in the previous chapter are taken up in that on The Economist, in particular the nature of web genres and the question of whether the blog is indeed a genre at all. In discussing these questions, Sandra Campagna, in "Antagonizing the editor: speech-styles variation in 
The Economist reader comments", draws largely on previous scholarship not mentioned previously, an indication of how rich and varied the field has become in the last ten years. The case study here is how readers react to editorial comment in The Economist, as exemplified by the editorials attacking the ban on the burqa in France and Belgium. The background information includes a discussion of what The Economist community is made up of, and how the well-known Economist style is reflected in readers' reactions. The thrust of the article is the evaluation of the extent to which these comments can be considered as an extension of the blog, and the linguistic features which characterise the texts are certainly cited, but hardly developed - structure is clearly felt to be the defining feature ("form not formalism") as the author points out.

The question of where blogs come from crops up in Małgorzata Sokót's "Metadiscourse and the construction of the author's voices in the blogosphere: academic weblogs as a form of self-promotion", this time in the guise, as the title clearly indicates, of the still relatively little studied academic blog. The author is in fact continuing an ambitious wide-ranging research project on other varieties of academic discourse, in particular digital genre development. The analysis presented here is based on a sample of eight single-author blogs from English studies, focusing on various manifestations of author presence. A breakdown of personal pronouns used shows a market similarity with etutorials but a differing use of we, in fact a tripartite division based on a decreasing range of inclusiveness. Citations are also examined to find out to what extent academic conventions are modified to benefit from the technological possibilities now offered by the web (yet another example of affordance). Generally speaking, though the expression is less constrained than in research articles, the conventions of academia are largely followed, but expressed in a multi-layered, polyphonic mode, suggesting a broader and more diversified readership than is the case for traditional academic publications.

13 The last two contributions focus on the commercial exploitation of microblogging, as exemplified by two strategies using Twitter. The first, Giorgia Riboni's "Twittering away: Whole Foods Market and conversational marketing in 140 characters", starts with an introduction to conversational marketing and pinpoints some of the strategies used by the American multinational referred to in the title, in particular the "exchanges" with their followers. The inverted commas are justified here by the difficulty in determining whether those who reply to the tweets are bona fide customers or simply company microbloggers. The question of why customers would even bother to reply is however addressed, the motivation put forward being one of self-promotion, which would account for a proportion (though an unknowable one) of genuine customer feedback. This article analyses pronoun use and explains the predominance of you (socalled "you style", page 296) by the interpretation that this rhetorical form is in fact part of promotional discourse.

The final chapter spells out how Coca Cola manipulates Twitter for promotional purposes. Maria Cristina Paganoni, in "Online branding from hybrid ads to corporate twittering", explains how creating a positive image of the brand and company comes across as the overriding motivation. The analysis is centred on the same three phases of microblogging as the previous chapter (tweets, replies and retweets), and investigates the cohesive and promotional use of proper names both that of the product and the user names of the followers. The chapter ends with a selection on the relatedness of microblogging and web-based communication on the whole and cautiously shows some 
reservations about the authenticity and "meaningfulness" of customer participation. The clearly manipulative use of micro blogging by commercial interests is well documented in the last two papers though the authors keep from incriminating the perpetrators of these manipulations.

The collection of essays is in fact remarkably coherent, thanks to the both chronological and thematic progression - and to careful editing. It is primarily an exploration of research possibilities, which gathers in a broad spectrum of studies in the many fields related to web communication, presents generally small-scale projects and from these suggests lines of research to be followed up. Almost all authors are at pains to point out how far existing theories can be extended to account for the fastmoving web communication scene, and the projects reported on reflect back on the adequacy of these theories. Most of the research presented here has a potential didactic application, but it is remarkable that only one chapter is devoted specifically to this subject.

In view of the revolutionary nature of the changes wrought by the innovations ushered in first by Web 1.0 and now Web 2.0, it is heartening to see that the work done by such researchers as Hyland, Swales and many others who have inspired ESP studies in Europe for many years is very much present in many of the chapters, suggesting that the basic theory of genres has stood up to this huge mutation, and that principles can still be used to follow the many more parameters linked with the hypermedia environment.

Many features are to be found running through many chapters, in particular genre theory and critical discourse analysis, the main tools used in analysis, but perhaps the most distinctive is that of affordance, which is mentioned in several papers but only defined in passing. There are Wikipedia articles on affordance in English, French and eight other languages, which point out how many meanings this term idiosyncratically derived from psychology - has taken on, in particular in web communication. Perhaps another theme for a further research project?

\section{BIBLIOGRAPHY}

Bakhtin, Mikhail Mikhailovich. 1982. The Dialogic Imagination. Four Essays by M.M. Bakhtin. Austin: University of Texas Press.

Bhatia, Vijay K. 2005. “Interdiscursivity in business letters". In Gillaerts, P. and M. Gotti (eds.), Genre Variation in Business Letters. Bern: Peter Lang.

Kachru, Braj B. 1986. The Alchemy of English. The Spread, Functions and Models of Non-native Englishes. Oxford: Pergamon.

Swales, John. 2004, Research Genres. Explorations and Applications. Cambridge: Cambridge University Press.

Vygotsky, Lev S. 1962. Mind and Society. The Development of Higher Psychological Processes. Cambridge, MA: Harvard University Press. 
AUTHORS

JOHN HUMBLEY

Université Paris Diderot, CLILLAC-ARP 